\title{
Time to first birth and its predictors among reproductive-age women in Ethiopia: inverse Weibull gamma shared frailty model
}

Reta Dewau ${ }^{{ }^{*} \mathbb{D}}$, Fantahun Ayenew Mekonnen² and Wullo Sisay Seretew ${ }^{2}$

\begin{abstract}
Background: High maternal and child death with high fertility rate have been reported in Ethiopia. Extreme age at first birth is linked with both maternal and child morbidity and mortality. However, literatures showed there were limited studies on the timing of the first birth and its predictors in the area so far. Therefore, determining the time to first birth and its predictors will help to design strategies to improve maternal and child survival.
\end{abstract}

Methods: A community-based cross-sectional study was conducted among reproductive-age women in Ethiopia using the Ethiopian demographic health survey, 2016 data. Stratified two-stage cluster sampling technique was used for sampling. The Kaplan-Meier method was used to estimate time to first birth. Inverse Weibull gamma shared frailty model applied to model the data at 95\% confidence interval (CI), adjusted hazard ratio (AHR) and median hazard ratio (MHR) were reported as effect size. Proportional hazard assumption checked using Schoenfeld residual test. Information Criteria were applied to select a parsimonious model. Stratified analysis performed for the interaction terms and statistical significance was declared at $p$ value $<0.05$.

Results: The overall median age at first birth was found to be 20 years (IQR, 16-24 years). The independent predictors of time to first birth were: married 15-17 years ( $A H R=2.33,95 \% \mathrm{Cl} 2.08-2.63)$, secondary education level ( $A H R=0.84$, $95 \% \mathrm{Cl} 0.78-0.96)$, higher education level $(\mathrm{AHR}=0.75,95 \% \mathrm{Cl} 0.65-0.85)$, intercourse before 15 years in the married stratum ( $A H R=23.81,95 \% \mathrm{Cl} 22.22-25.64)$, intercourse 15-17 years in married stratum ( $A H R=5.56,95 \% \mathrm{Cl}$ 5.26-5.88), spousal age difference (AHR $=1.11,95 \% \mathrm{Cl} 1.05-1.16)$, and use of contraceptives (AHR $=0.91,95 \% \mathrm{Cl} 0.86-0.97)$. The median increase in the hazard of early childbirth in a cluster with higher early childbirth is $16 \%(\mathrm{MHR}=1.16,95 \% \mathrm{Cl}$ 1.13-1.20) than low risk clusters adjusting for other factors.

Conclusion: In this study, first birth was found to be at an early age. Early age at first marriage, at first sexual intercourse and their interaction, high spousal age difference, being Muslim were found to increase early motherhood. Conversely, living in the most urban region, secondary and higher women education were identified to delay the first birth. Investing on women education and protecting them from early marriage is required to optimize time to first birth. The contextual differences in time to first birth are an important finding which requires more study and interventions.

Keywords: Time to first birth, Predictors, Reproductive age-women, Ethiopia

\section{${ }^{*}$ Correspondence: retadewau30@gmail.com}

${ }^{1}$ Department of Epidemiology and Biostatistics, School of Public Health, College of Medicine and Health Science, Wollo University, Dessie, Ethiopia Full list of author information is available at the end of the article

\section{Background}

Age at first birth refers to the age of a mother when she gave birth to her first child [1,2]. Attaining the first child is one of the most important events in a woman's 
life. It indicates the beginning of the intensive responsibilities of maternity and childcare [3].

Roughly 1 in 10 childbirths contributed by young mothers worldwide and of these, developing countries accounting $95 \%$ of the share [4]. Girls under 15 years account for 2 million (27\%) of the 7.3 million births that occur to adolescent girls below s18 years in developing countries [5].

When a woman became pregnant in the adolescent period, her present and future life rarely became for better $[5,6]$. It results in cessation of education, joblessness, deprived maternal and child health outcomes, an numerous children per women, gender inequity, destitution of adolescent mothers and their families and the communities at large [2, 5, 7-13]. Worldwide over half a million $(500,000)$ women aged $15-49$ years die annually from preventable pregnancy-related complications [14]. Furthermore, girls under 15 years are five times at higher risk of death and those 15-19 years are twice more likely to die than women aged 20-24 years in pregnancy or childbirth $[15,16]$. Complications from Pregnancy and childbirth are the primary cause of decease (1 out of 7 girls) among under 19 years in third world countries [17].

On the other hand, advanced maternal age ( $>30$ years) at first birth is linked with an higher risk of miscarriage, chromosomal anomalies, multiple pregnancies, hypertension, diabetes mellitus, preterm birth, low birth weight, breast cancer and maternal mortality $[16,18,19]$. Those who gave first birth at 30 years and above group were $33 \%$ at higher risk of mortality compared to those who gave first birth in the age group 20-24 years in Ohsaki Japan [16]. The impacts of urbanization and modernization postponed the age at first birth in the later age in the developed world [9, 20-22].

Worldwide $20 \%$ of women give birth by the age of 18 , in the poorest regions of the world, this rises to beyond a third (35\%) in Kenya [14]. The median age at first birth in East Asia and Pacific was 20.2 years in Martial Island in 2007 and 23.4 years in Samoa in 2009 [8] in Bangladesh the mean age at first birth is 17.92 years [23], in Ghana 19.91 years in 2008 [24]. The median age at first birth in Nigeria was 20 years in 2013 [25]. In Ethiopia, more than a third (34\%) of women age $20-49$ give birth by the age of 18 and $54 \%$ by their age of 20 [22].The mean age of women at first birth was 18.47 years in Degua Tembien District, Tigray, Ethiopia [26].

There are numerous factors for this high prevalence of poor maternal and child health in third world nations. This includes deep-seated socio-cultural and spiritual practices, illiteracy and reduced income $[13,15,16,25$, $27,28]$. Non-Muslim women have first births latter than women $[23,25]$.
Socio-demographic factors that were recognized as a predictor of age at first birth in various literatures include early age at first sexual intercourse [9, 20,24], high Spousal age gap [5, 23, 29]. Some of the studies revealed that age at first birth at a lower age is higher in a woman of having wide Spousal age difference [5, 23, 29]. The younger age at first marriage is one of the most consistent findings across the studies as a risk factor for early age at first birth $[5,6,9$, $14,17,21,23-25,28,30-35]$.

The Socio-economic factors were identified as a predictor of age at first birth as consistent manner. As many studies showed that the probability of early age at first birth is higher in women with no or lower level education compared to women at a higher educational level $[1,5,6,9,14$, $17,20,21,23-25,29,32-34,36,37]$. Most of the studies revealed that having poor and middle wealth index status was identified as the risk of age at first birth in early age.

Childbirth is being delayed to a later age with the mean age at first birth 26.3 years in the United States America (USA) [38] to 30 years in Britain [3]. The majority works of the literature revealed that the use of any contraception delay age at first birth $[5,8,9,23-25,30,39-41]$.

For most populations having first marriage at a lower age tend to have early childbearing and high fertility $[6,25]$. On top of that in modern times many children are born before marriage with numerous health risks, like abortion and HIV [42]. The prevalence of premarital conceptions is $1 \%$ in Tanzania [43] and 1.2\% in Ethiopia [44].

Even though the timing of first birth measured by the age at first birth has a huge effect on maternal and child survival, both individual and cumulative levels of fertility, as well as extensive implications on, women's roles and social changes in general, studies conducted in Ethiopia on this topic are scarce. Furthermore, those limited studies conducted on teenage pregnancy [35] and age at first birth after marriage [34] did not account births outside marriage and first birth beyond adolescent period. Knowledge on the timing and factors of first birth in the country will help to design proper strategies to improve maternal and child health. Thus, by considering the above limitations this study is designed to estimate time to first birth and identify predictors among all reproductive-age women regardless of their marital status in Ethiopia with taking into account the correlated nature of the data. So, the study will serve for the next researchers and program planners to improve both maternal and child health with consideration of contextual/cluster effects.

\section{Methods}

\section{Study design}

Community based Cross sectional survey was conducted from January 18, 2016 to June 27, 2016 among reproductive-age women in Ethiopia [44]. 


\section{Study area and period}

The study was conducted in Ethiopia one of the SubSaharan African country where the maternal mortality ratio 412 per 100,000 live births, skilled delivery coverage $28 \%$,the median age at first marriage 17.1 years and the median age at first sexual intercourse 16.6 years, the contraceptive prevalence among married 36\%, sexually active unmarried women 58\% [44]. The estimated population in 2016 was 102 million with a fertility rate of 4.46 and the second largest population in Africa. The majority (78\%) of women lived in rural [44]. The study was conducted from January 18 to June 27, 2016.

\section{Study participants}

The study included all reproductive age-women (1549 years) found in the selected clusters at least one night before data collection period January 18, 2016 to June 27, 2016. Taking reproductive age-women (1549 years) of Ethiopian in place of source population, reproductive age women living in selected clusters as study population and reproductive age-women (1549 years) found in 2016, Ethiopian demographic health survey (EDHS) enumeration areas at least one night before data collection as per Sample population [44]. Women declared infecund were excluded.

\section{Operational definitions}

Access to media Respondents were asked how often they read a newspaper, listened to the radio, or watched television. Those who had exposure to one of them at least once a week are considered being regularly exposed to media [44, 45].

Time to first birth refers to the age of a mother in years when she gave birth to the first child after puberty $[1,2,38]$.

Censored Those women who did not gave birth until the 2016 EDHS data collection end date.

Event/Uncensored mothers who gave first birth until 2016 EDHS data collection end date.

Declared infecund married or in union women for $5+$ years, had no children in the past 5 years and never used contraception [45].

Time to event/waiting time it is the time in years from puberty to age at first birth.

Beginning time women at puberty (10 years from her birth date).

\section{Sampling technique and sample size determination}

The 2016 EDHS sample was selected using stratified two-stage cluster sampling design and census enumeration areas (EAs) were the sampling units for the first stage and the detail published [46].

A total of 18,008 households were selected for the sample, of which 17,067 were occupied. Of the occupied households, 16,650 were successfully interviewed, yielding a response rate of $98 \%$. In the interviewed households, 16,583 eligible women were identified for individual interviews. Interviews were completed with 15,683 women, yielding a response rate of $95 \%$ [44].

After the exclusion of primary infertile (57 women) from the data, the effective sample size became 15,626 (Fig. 1).

\section{Dependent and independent variable}

The dependent variable in the current study is time to first birth in years when a woman gave her first childbirth until data collection period. The independent variables included, socio-demographic and reproductive health related factors (Age at first sexual intercourse, age at first marriage, Ever married, Spousal age difference); socioeconomic and information related factors (respondent's education, respondent's occupation, Husband's education, Husband occupation, Wealth index and Mass media exposure); Community level factors (region and residence) and Use of contraception as an immediate factor [46].

\section{Data source}

For this study secondary data from the 2016 EDHS was used. The data set downloaded from the website https://dhsprogram.com after approval letter for use had obtained from the measure DHS. Variables were

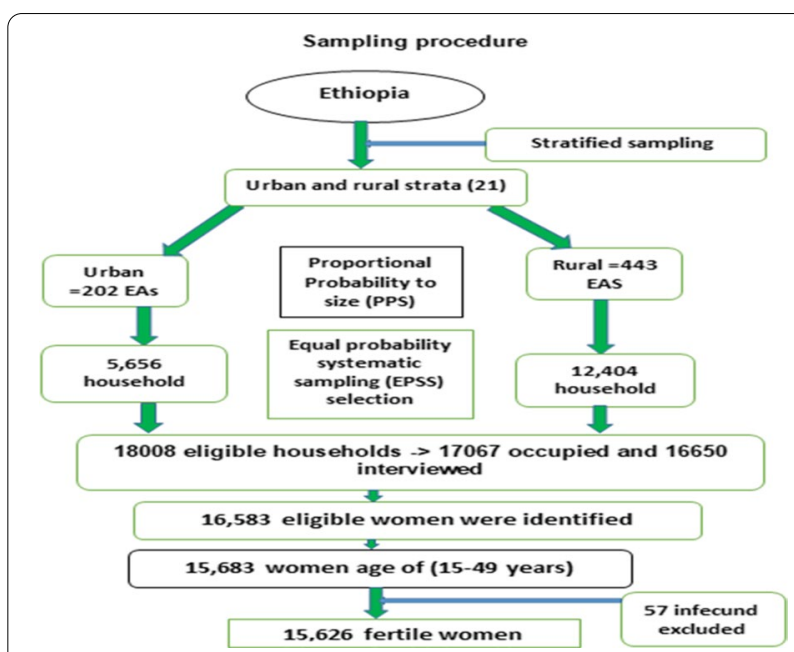

Fig. 1 Sampling procedure of time to first birth and its predictors among reproductive age women in Ethiopia, 2016 EDHS 
extracted from the EDHS 2016 individual women's data set using a data extraction tool.

\section{Measurement of variables}

Dependent variable, time to first birth measured in years was taken from age at first birth for mothers at least gave their first birth and the current age of respondent for event censored women. For the purpose of analysis those women gave birth event coded 1 (success) and those who did not give birth 0 (censored).

Independent variables age at first sexual intercourse and age at first marriage classified in to three categories; less than $15,15-17$ and 18 and above years, the highest age category taken as reference. Ever married coded as married and not married. Spousal age difference categorized as less than 5 years and 5 and above years. Respondent's and husband education categorized into (no education, primary, secondary and higher education) and no education taken as reference. Respondent's and husband occupation coded as not working, agriculture and non-agriculture with non-agriculture reference. Wealth index was classified as (poorest, poor, middle, richer and richest) by taking poorest as comparison group. Mass media exposure (yes/no), and use of contraception (yes/no). The regions were classified into six categories because there socio-cultural and economic similarities and geographical relations of the regions. These are northern regions (Amhara and Tigray), Oromia, Southern Nations, Nationalities and Peoples (SNNP), eastern pastoralist referring to the pastoralist dominant Afar and Somali regions, western region semi pastoralist representing Gambella and Benishangul-Gumuz, and most urban regions representing (Addis Ababa and Dire Dawa city administrations and Harari), while residence classified as urban and rural [46].

\section{Data quality control}

After all, questionnaires were finalized in English; they were translated into local languages (Amarigna, Tigrigna, and Oromiffa) and pretested at Bisheftu. Computerassisted personal interview data collection system was carried out to collect data by trained EDHS data collectors and mobile version CSPro software was used for entering and capturing the data [44].

For this study the same source population used for both those who gave birth or not to make comparable. The data collectors and study participants were blind to the study hypothesis since the analysis considered later. Data extraction checklist was prepared and data extracted using Stata version 14.0.

\section{Data analysis}

After the data were extracted, cleaned and weighted descriptive measures such as median, percentiles, graphs and frequency tables were used to characterize the study population. We estimated time to first birth using the Kaplan-Meier $(\mathrm{K}-\mathrm{M})$ method and compared across categorical predictor variables using log rank test. Schoenfeld residual test was applied to check the proportional hazard assumption.

Since our data were correlated at cluster level, shared frailty model were modeled by taking enumeration areas/ clusters as a random effect for predictors of time to first birth among reproductive-age women in Ethiopia assuming time to first birth to be constant in the same clusters. The efficient model was selected by the smallest AIC value. Model adequacy was checked using Akaike Information Criteria (AIC), Cox-Snell residuals and $R^{2}$ type statistic.

Stratified analysis and chi-square test were applied for interaction terms. Finally adjusted hazard ratio (AHR) and adjusted time ratio (ATR) as a measure of effect size reported at $5 \%$ significant level and $p$ value $<0.05$.

Stata 14.0/SE software for data extraction, cleaning and analysis was used.

\section{Measures of dependence in shared frailty modeling}

The associations within group members are measured by Kendall's, which is given by

$$
\tau=\frac{\theta}{\theta+2}
$$

where $\tau \varepsilon[0,1]$.

For Gamma frailty distribution $(\theta>0)$

$$
\tau=\frac{1}{2}-\frac{1}{\theta}+\frac{2}{\theta^{2}} e^{\left(\frac{2}{\theta}\right)} \int_{2 / \theta}^{\infty} u^{-} e^{(-u)} d u<\frac{1}{2}
$$

where $\tau \varepsilon(0,1 / 2)$.

For Inverse Gaussian frailty distribution $(\theta>0)$.

The median hazard ratio (MHR) was used to compare between high and low risk clusters of time to first childbirth

$\operatorname{MHR}=e^{\left(\sqrt{2 \theta} * \Phi^{-1} *\left(\frac{3}{4}\right)\right)}$ where $\theta=$ variance of frailty, $\Phi$ ${ }^{-1}=$ inverse normal distributions.

\section{Ethical consideration}

The written approval letter was obtained from the DHS International Program to use the data for this analysis which authorized for the data-sets. Before data collection EDHS data collection materials were approved for compliance of the requirements of 45 CFR 46, "Protection of Human Subjects" by Institutional Review Board (IBR) 
with ICF Project Number: 132989.0.000.ET.DHS.01. Complete information regarding the ethical issue was available in the EDHS-2016 report [44].

\section{Results}

\section{Baseline characteristics of study participants}

A total of 15,626 (weighted $=15,635$ ) women were included in the study. From the respondents one fifth (21.62) were adolescents. Of all, the majority $(77.88 \%)$ of them were rural in residence. Of married women, $67.37 \%$ had more than 5 years of a spousal age difference. Around two-thirds (63\%) of women married their first husband before their age of 18 years. Moreover, $26.24 \%$ of them married before the age of 15 years (Table 1 ).

Regarding socio-economic and information related characteristics of the respondents, $47.77 \%$ of them had no education and $49.91 \%$ have no formal occupation. More than $34 \%$ of the study participants had wealth index status below the middle level and only a quarter $(26.37 \%)$ had regular media exposure (Table 2).

Table 1 Socio-demographic and reproductive health-related factors among reproductive age women in Ethiopia, EDHS 2016

\begin{tabular}{|c|c|c|c|}
\hline Variables & Categories & $\begin{array}{l}\text { Weighted } \\
\text { frequency }\end{array}$ & $\begin{array}{l}\text { Weighted } \\
\text { percentage } \\
(\%)\end{array}$ \\
\hline \multirow{3}{*}{$\begin{array}{l}\text { Age distribution } \\
\qquad(N=156,356)\end{array}$} & $<20$ years & 3380 & 21.62 \\
\hline & 20-29 years & 5716 & 36.56 \\
\hline & $>30$ years & 6539 & 41.82 \\
\hline \multirow[t]{2}{*}{ Residence } & Urban & 3447 & 22.12 \\
\hline & Rural & 12,175 & 77.88 \\
\hline \multirow[t]{6}{*}{ Regions } & Most urban & 1042 & 6.74 \\
\hline & Northern & 4827 & 30.87 \\
\hline & Oromia & 5682 & 36.34 \\
\hline & SNNp & 3282 & 21.00 \\
\hline & Eastern-pasto & 585 & 3.74 \\
\hline & Western-Pasto & 204 & 1.30 \\
\hline \multirow{3}{*}{$\begin{array}{l}\text { Age at first intercourse } \\
(\mathrm{n}=15,635)\end{array}$} & $<15$ years & 3027 & 19.36 \\
\hline & $15-17$ years & 5062 & 32.38 \\
\hline & $>18$ years & 7546 & 48.26 \\
\hline \multirow{3}{*}{$\begin{array}{l}\text { Age at first marriage } \\
\qquad(\mathrm{n}=11,600)\end{array}$} & $<15$ years & 3044 & 26.24 \\
\hline & $15-17$ years & 4256 & 36.69 \\
\hline & $>18$ years & 4300 & 37.07 \\
\hline \multirow[t]{2}{*}{ Spousal age difference } & $<5$ years & 3326 & 32.63 \\
\hline & $>5$ years & 6867 & 67.37 \\
\hline Contraceptive & Ever not use & 8895 & 56.95 \\
\hline \multirow[t]{5}{*}{$(\mathrm{n}=15,635)$ religion } & Ever use & 6727 & 43.05 \\
\hline & orthodox & 6,762 & 43.25 \\
\hline & Muslim & 4,881 & 31.22 \\
\hline & protestant & 3,662 & 23.42 \\
\hline & Others $^{\mathrm{a}}$ & 330 & 2.11 \\
\hline
\end{tabular}

a Others $=$ catholic, traditional and other
Table 2 Socio-economic and information related characteristics among reproductive age women in Ethiopia EDHS, 2016

\begin{tabular}{|c|c|c|c|}
\hline Predictors & Categories & $\begin{array}{l}\text { Weighted } \\
\text { frequency }\end{array}$ & $\begin{array}{l}\text { Weighted } \\
\text { percentage } \\
(\%)\end{array}$ \\
\hline \multirow[t]{4}{*}{ Education } & No education & 7469 & 47.77 \\
\hline & Primary & 5475 & 35.04 \\
\hline & Secondary & 1802 & 11.61 \\
\hline & Higher & 868 & 5.57 \\
\hline \multirow[t]{3}{*}{ Occupation } & Not working & 7799 & 49.91 \\
\hline & Agriculture employee & 3248 & 20.77 \\
\hline & $\begin{array}{l}\text { None agriculture } \\
\text { employee }\end{array}$ & 4576 & 29.32 \\
\hline \multirow[t]{4}{*}{ Husband education } & No education & 4750 & 46.60 \\
\hline & Primary & 3765 & 36.94 \\
\hline & Secondary & 971 & 9.53 \\
\hline & Higher & 707 & 6.94 \\
\hline \multirow[t]{3}{*}{ Husband occupation } & Not working & 802 & 7.87 \\
\hline & Agriculture employ & 6323 & 61.93 \\
\hline & Non-agri-employe & 3078 & 30.20 \\
\hline \multirow[t]{2}{*}{ Media exposure } & Yes & 4115 & 26.37 \\
\hline & No & 11,508 & 73.63 \\
\hline \multirow[t]{5}{*}{ Wealth index } & Poorest & 2630 & 16.82 \\
\hline & Poorer & 2803 & 17.93 \\
\hline & Middle & 2968 & 18.98 \\
\hline & Richer & 3092 & 19.77 \\
\hline & Richest & 4143 & 26.49 \\
\hline
\end{tabular}

Time to first birth among study participants

Over all 10,274 (67.7\%) women had given at least first birth. The total follow-up period for all 15,626 women was 146,290 person-years of observation. The median, minimum and maximum follow-up period was 8 years 1 year and 39 years after the age of puberty (10 years from her birth date), respectively. The overall median time to first birth was 20 years (IQR $=16-24)$. Among women had first birth below 20 years the median age was 18 years ( $\mathrm{IQR}=15-19)$, from those women giving first birth in the age bracket of 20-29 years median age was 23 years $(I Q R=20-26)$ and of women celebrate their 30 years before giving birth $(n=533)$ only $49.5 \%$ able to give birth (Fig. 2).

The median time to first birth was at lower age for those women enter into sexual intercourse at lower age ( $<15$ years) 15 years (IQR $=13-17)$, too early married women (below 15 years) 16 years $(\mathrm{IQR}=14-17)$ and women had no education 18 years (IQR $=15-21$ ) years (Table 3 ). The median age was relatively higher among women those had higher education level 27 years $(\mathrm{IQR}=21--)$. 
a

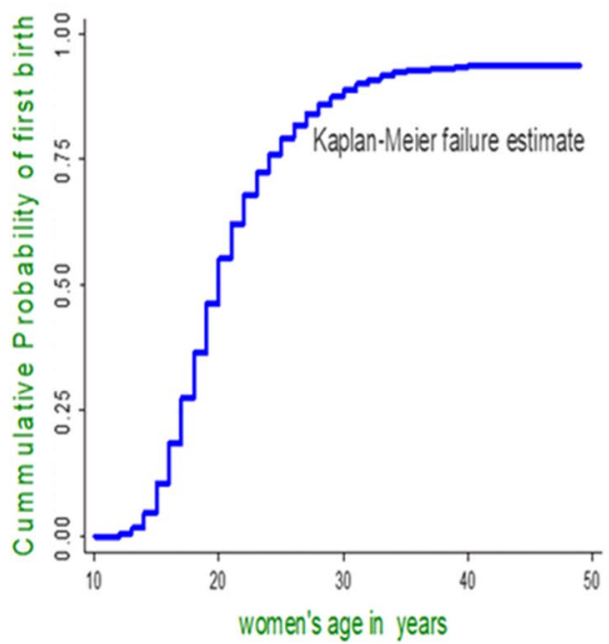

b

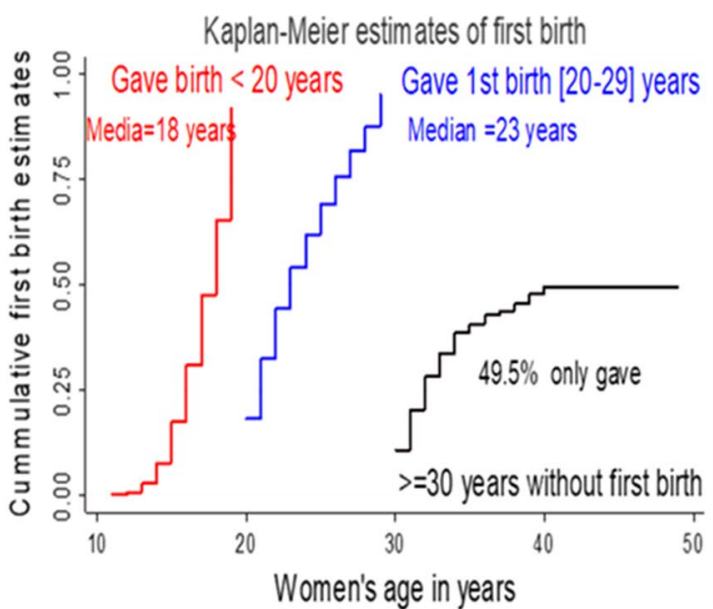

Fig. 2 Kaplan-Meier failure estimates of time to first birth among reproductive-age women in Ethiopia, 2016 EDHS. a Overall Kaplan-Meier failure estimate. $\mathbf{b}$ Early, optimal and advanced age at first birth estimates among respondents

\section{Predictors of time to first birth among reproductive-age women in Ethiopia, 2016 EDHS}

Differences in all predictors at baseline were determined using the Kaplan Meier failure function and the log-rank $\left(\chi^{2}\right)$ test. The Kaplan Meier failure function with $95 \%$ confidence interval was constructed for age at first marriage and women education level (Fig. 3).

In general, the pattern of the failure function lying below right side to other categories indicated that the group defined by the lower curve had a better survival before giving first birth than the group defined by the above curves. Therefore women married at the age of 18 and above years and women with secondary and higher education level able to delay their first birth in the later age than married below 18 years and below secondary education level respectively as Kaplan Meier failure graph and a log-rank test at $(p$ value $<0.001)$ showed. The log-rank test showed that all predictor variables had a significant survival difference at $p$ value $<0.001$ (Table 3 ).

\section{Parsimonious model selection}

\section{Cox proportional hazard model}

All fourteen predictor variables that were significant at $0.2 p$ value in Bivariable analysis were entered into the multivariable Cox model and ever married reduced from the model due to collinearity effect. Then the Schoenfeld test for proportional hazard assumption of the time to first birth data was evaluated. The proportional hazard assumption violated in both global test and rank test due to significant correlation of time to first birth (Table 4), as a result, the Cox model was excluded for this data.

Stratified Cox model was also inappropriate for this data because there is no predictor variable that fulfills proportional hazard assumption to be in the model. Another alternative time-varying Cox model also faces the challenge of choosing the appropriate function of survival time to include in the model. However, in the case of our data, the time distribution is somewhat follow unimodal distribution (Fig. 4). So, those parametric models were considered.

\section{Appropriate parametric survival model selection Parametric shared frailty model}

A likelihood ratio test for a variance of frailty theta $=0$ yields a highly statistically significant $p$ value of $<0.001$ for all baseline hazard function with both inverse Gaussian and gamma shared frailty distributions, suggesting that the frailty component contributes to the model and that there is a within-cluster correlation. The inverse Weibull gamma shared frailty model is preferred model for the give data due to its lowest AIC (Table 5).

\section{Multivariable analysis of inverse Weibull gamma shared frailty model for time to first birth and its predictors} among reproductive-age women in Ethiopia, EDHS, 2016 In the inverse Weibull gamma shared frailty model, the null model, only with the cluster effect and the full model, with predictor factors were compared to visualize reduction of frailty variance on the addition of predictor 
Table 3 Kaplan-Meier failure estimate and log rank test comparison of time to first birth among reproductive age women in Ethiopia, 2016 EDHS

\begin{tabular}{|c|c|c|c|c|c|}
\hline Characteristics & $N(\%)$ & Ever given birth & Median (IQR) years & Log-rank & $p$ value \\
\hline \multicolumn{6}{|l|}{ Region } \\
\hline Northern & $4827(30.87)$ & $3224(66.8)$ & $19[16-24]$ & \multirow[t]{6}{*}{570.2} & \multirow[t]{6}{*}{$<0.001$} \\
\hline Oromia & $5682(36.34)$ & $4130(72.7)$ & 19 [16-22] & & \\
\hline SNNPR & $3282(21.00)$ & $2192(66.8)$ & $20[16-24]$ & & \\
\hline Most-urban & $1042(6.74)$ & $474(45.5)$ & 26 [19-34] & & \\
\hline Eastern-pasto & $585(3.74)$ & $424(72.4)$ & 19 [16-22] & & \\
\hline Western-semi Pasto & $204(1.30)$ & $144(70.7)$ & 19 [16-22] & & \\
\hline \multicolumn{6}{|l|}{ Residence } \\
\hline Urban & $3447(22.12)$ & $1769(51.3)$ & 23 [18-30] & \multirow[t]{2}{*}{916.7} & \multirow[t]{2}{*}{$<0.001$} \\
\hline Rural & $12,175(77.88)$ & $8818(72.4)$ & 19 [16-22] & & \\
\hline \multicolumn{6}{|l|}{ Education } \\
\hline No education & $7469(47.77)$ & $6785(90.9)$ & 18 [15-21] & \multirow[t]{4}{*}{2545.8} & \multirow[t]{4}{*}{$<0.001$} \\
\hline Primary & $5475(35.04)$ & $2865(52.3)$ & $20[17-24]$ & & \\
\hline Secondary & $1802(11.61)$ & $593(32.8)$ & $26[20-37]$ & & \\
\hline Higher & $868(5.57)$ & $344(39.6)$ & 27 [21-49] & & \\
\hline \multicolumn{6}{|l|}{ Occupation } \\
\hline Not working & 7799 (49.91) & $5243(67.2)$ & 19 [16-23] & \multirow[t]{3}{*}{461.0} & \multirow[t]{3}{*}{$<0.001$} \\
\hline Agriculture & $3248(20.77)$ & $2522(77.6)$ & $19[15-21]$ & & \\
\hline Non agricul- & $4576(29.32)$ & $2822(61.8)$ & 21 [17-27] & & \\
\hline \multicolumn{6}{|l|}{ Wealth index } \\
\hline Poorest & $2630(16.82)$ & $2060(78.3)$ & 19 [16-22] & \multirow[t]{5}{*}{903.9} & \multirow[t]{5}{*}{$<0.001$} \\
\hline Poorer & $2803(17.93)$ & $2122(75.7)$ & $19[16-21]$ & & \\
\hline Middle & $2968(18.98)$ & $2128(71.7)$ & 19 [16-22] & & \\
\hline Richer & $3090(19.76)$ & $2089(67.6)$ & 19 [16-23] & & \\
\hline Richest & 4131 (26.49) & $2190(53.0)$ & 22 [17-30] & & \\
\hline \multicolumn{6}{|l|}{ Contraceptive } \\
\hline Ever not use & $8895(56.95)$ & $4617(51.9)$ & $21[17-26]$ & \multirow[t]{2}{*}{844.2} & \multirow[t]{2}{*}{$<0001$} \\
\hline Ever use & $6727(43.05)$ & $5970(88.7)$ & 19 [16-22] & & \\
\hline \multicolumn{6}{|l|}{ Media exposure } \\
\hline No & $11,508(73.63)$ & $8342(72.5)$ & 19 [16-22] & \multirow[t]{2}{*}{576.6} & \multirow[t]{2}{*}{$<0.001$} \\
\hline Yes & $4115(26.37)$ & $2245(54.6)$ & 22 [17-28] & & \\
\hline \multicolumn{6}{|l|}{ Ever married } \\
\hline No & $4022(25.81)$ & $93(2.3)$ & - & 3974.7 & $<0.001$ \\
\hline Yes & $11,600(74.19)$ & $10,494(90.5)$ & 19 [15-21] & & \\
\hline Spousal age gap & & & & & \\
\hline$<5$ years & $3326(32.63)$ & $2984(89.7)$ & 19 [16-22] & 129.2 & $<0.001$ \\
\hline$\geq 5$ years & $6,867(67.37)$ & $6366(92.7)$ & $18[15-21]$ & & \\
\hline Age at first marriage & & & & & \\
\hline Below age 15 & $3044(26.24)$ & 2915 (95.8) & $16[14-17]$ & 5582.3 & $<0.001$ \\
\hline $15-17$ & $4256(36.69)$ & $3890(91.4)$ & 18 [16-19] & & \\
\hline 18 and above & $4300(37.07)$ & 3689 (85.8) & 22 [19-25] & & \\
\hline Age at first sex & & & & & \\
\hline$<15$ years & $3027(19.36)$ & $2860(94.47)$ & 15 [13-18] & & \\
\hline $15-17$ years & $5062(32.38)$ & $4576(90.4)$ & 18 [16-20] & & \\
\hline$\geq 18$ years & $7546(48.26)$ & $3151(41.75)$ & 22 [19-26] & & \\
\hline Husband-education & & & & & \\
\hline No education & $4750(46.60)$ & $4516(95.1)$ & $18[15-21]$ & 396.1 & $<0.001$ \\
\hline Primary & $3765(36.94)$ & $3454(91.7)$ & 18 [15-21] & & \\
\hline
\end{tabular}


Table 3 (continued)

\begin{tabular}{|c|c|c|c|c|c|}
\hline Characteristics & N (\%) & Ever given birth & Median (IQR) years & Log-rank & $p$ value \\
\hline Secondary & $971(9.53)$ & $808(83.2)$ & 20 [16-23] & & \\
\hline Higher & 707 (6.94) & $573(81.1)$ & 21 [17-25] & & \\
\hline \multicolumn{6}{|l|}{ Husband occupation } \\
\hline Not working & $802(7.87)$ & $740(92.3)$ & 18 & 256.1 & 0.001 \\
\hline Agriculture employee & $6323(61.93)$ & $5930(93.9)$ & 18 & & \\
\hline Nonagriculture & $3078(30.20)$ & $2681(87.1)$ & 19 & & \\
\hline \multicolumn{6}{|l|}{ Religion } \\
\hline Orthodox & $6762(43.25)$ & $4371(64.6)$ & 20 & 178.6 & $<0.001$ \\
\hline Muslim & $4881(31.22)$ & $3593(73.6)$ & 19 & & \\
\hline Protestant & $3662(23.42)$ & $2367(64.7)$ & 20 & & \\
\hline Others & $330(2.11)$ & $255(77.1)$ & 19 & & \\
\hline Total & 15,635 & $10,635(67.7)$ & $20[16,24]$ & & \\
\hline
\end{tabular}

$N$ weighted value, IQR interquartile range
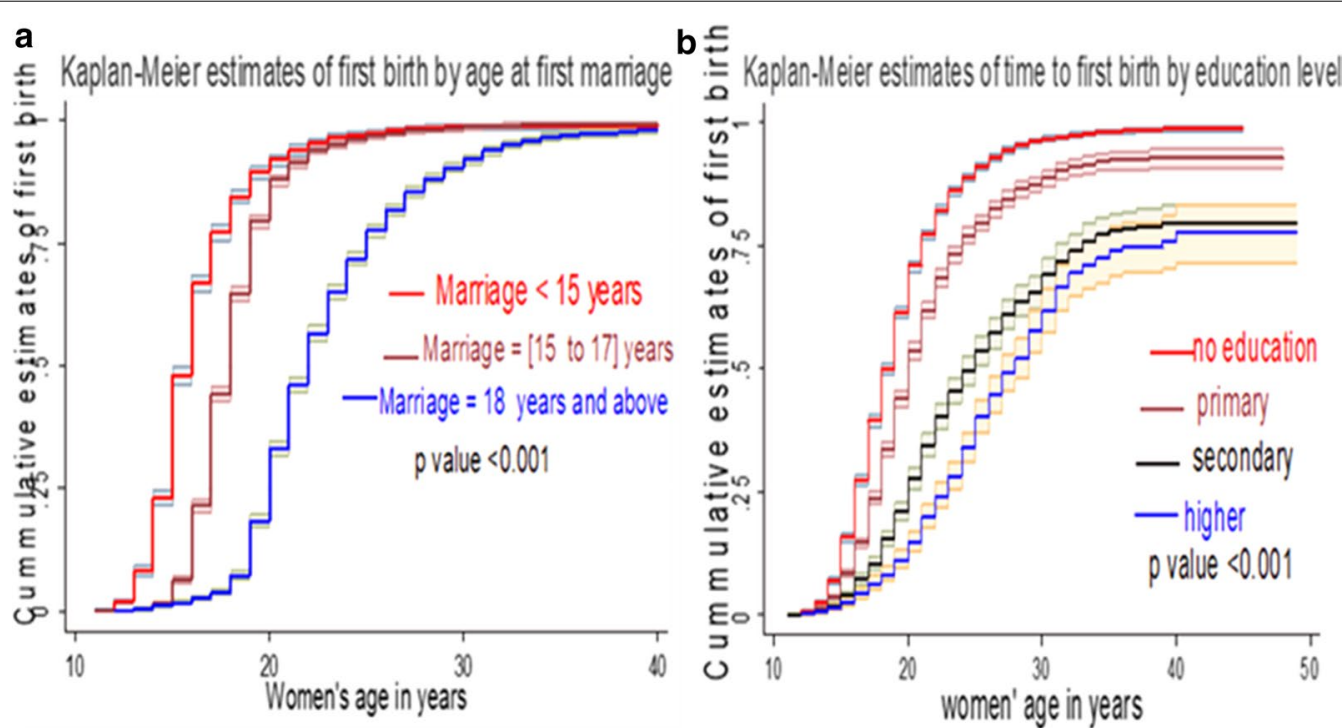

Fig. 3 Kaplan-Meier failure estimates difference and log-rank equality of survival tests of time to first birth among reproductive-age women in Ethiopia, 2016, EDHS. a Kaplan-Meier estimate of time to first birth by age at first marriage. b Kaplan-Meier estimate of time to first birth by education level

variables which revealed that in the full model variance theta reduced from null model $0.05-0.028$ and 0.025 . In this model predictor variables geographical regions, women education level, contraceptive use, spousal age difference, age at first marriage, age at first sexual intercourse, religion and age at first sexual intercourse interaction with age at first marriage, were significant predictor variables at $95 \%$ confidence level.

Having the same frailty or cluster effect living in Oromia increased the hazard of early childbirth by $18 \%(\mathrm{AHR}=1.18,95 \%, \mathrm{CI} 1.06-1.30)$; living in SNNP increased the hazard of early childbirth by $19 \%(\mathrm{AHR}=1.19$, 95, CI 1.06-1.30); living in Eastern pastoralist region increased the hazard of early childbirth by $16 \%(\mathrm{AHR}=1.16,95 \%, \mathrm{CI} 1.05-1.28)$ and living in western semi pastoralist regions increased the hazard of early childbirth by $37 \%$ (AHR $=1.37,95 \%$, CI 1.24-1.52) than living in most urban regions controlling for other factors.

With the same level of frailty and adjusting for the other factors women having secondary and higher education level have $14 \%(\mathrm{AHR}=0.86,95 \% \mathrm{CI} 0.78-0.96)$ and $25 \%(\mathrm{AHR}=0.75,95 \%$ CI $0.65-0.85)$ hazard reduction of first birth at early age compared to women with no education level respectively. 
Table 4 Schoenfeld residual test for proportionality assumption of the Cox model

\begin{tabular}{lrrrl}
\hline Predictors & \multicolumn{1}{l}{ Rho } & \multicolumn{1}{c}{ Chi $^{2}$} & $d f$ & Prob $>$ chi $^{2}$ \\
\hline Geo-regions & 0.056 & 91.18 & 1 & $<0.001$ \\
Residence & -0.078 & 174.81 & 1 & $<0.001$ \\
Religion & -0.061 & 82.37 & 1 & $<0.001$ \\
Education level & 0.071 & 107.88 & 1 & $<0.001$ \\
Occupation & -0.055 & 80.36 & 1 & $<0.001$ \\
Wealth index & -0.095 & 235.12 & 1 & $<0.001$ \\
Spousal age difference & -0.108 & 231.14 & 1 & $<0.001$ \\
Contraceptive use & 0.193 & 1009.79 & 1 & $<0.001$ \\
Media exposure & 0.030 & 20.33 & 1 & $<0.001$ \\
Age first marriage & 0.220 & 1589.96 & 1 & $<0.001$ \\
Age first sex & 0.138 & 463.55 & 1 & $<0.001$ \\
Husband education & -0.066 & 118.00 & 1 & $<0.001$ \\
Husband occupation & 0.019 & 13.02 & 1 & $<0.001$ \\
Global test & & 6191.37 & 13 & $<0.001$ \\
\hline
\end{tabular}

$<0.001$ means significant at $5 \%$ significance level; proportionality assumption is violated

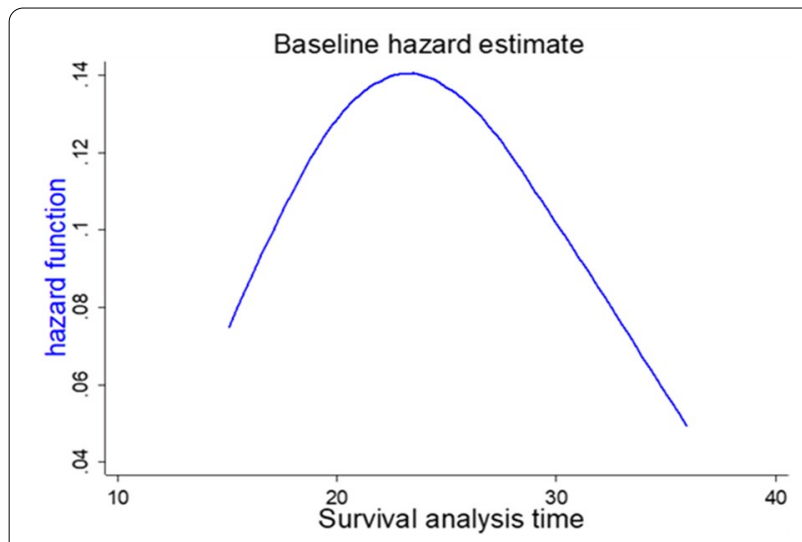

Fig. 4 Base line hazard estimate of time to first birth among reproductive-age women in Ethiopia, 2016, EDHS

Women with richer wealth index were had 10\% higher hazard of first birth at an early age compared to those women with poorest wealth index keeping other factors constant and in the same frailty level (AHR $=1.10,95 \%$, CI 1.01-1.19).

Women living in the same cluster and adjusted for other factors women ever using any methods of contraceptive to delay first birth reduces the hazard of first birth at an early age by 0.91 times compared to ever non-users (AHR $=0.91,95 \%$ CI 0.86-0.97).

Adjusting for other factors and women in the same frailty having spousal age difference greater than 5 years had $11 \%$ higher hazard of first birth at an early age compared to women having spousal age difference less than 5 years $(\mathrm{AHR}=1.11,95 \%$ CI $1.05-1.16)$.

At the same level of susceptibility and holding constant other factors women who were married 15-17 years had $2.33(\mathrm{AHR}=2.33,95 \%, \mathrm{CI} 2.08-2.63)$ times higher hazard of first birth at early age compared to women those who were married 18 years and above respectively.

The hazard of first birth at an early age was increased by $(\mathrm{AHR}=23.81,95 \%$, CI 22.22-25.64) times in married stratum and reduced by $(\mathrm{AHR}=0.063,95 \%, \mathrm{CI}$ 0.035-0.11) time in not married stratum among women who were started sexual intercourse earlier than 15 years than those women started sexual intercourse at the age of 18 years and later with marriage in the same level frailty level and making constant other factors. The hazard of early childbirth was higher among women who were stated intercourse 15-17 years in marriage by $(\mathrm{AHR}=5.56,95 \%, \mathrm{CI} 5.26-5.88)$ and it was reduced by $(\mathrm{AHR}=0.033: 95 \%, \mathrm{CI} 0.022-0.048)$ in those started intercourse before marriage than those who were started sexual intercourse in marriage at the age of 18 years and later.

Prior to adjusting for predictors the median increase in the hazard of early childbirth when comparing a woman at a cluster with higher risk of early childbirth to a woman at a cluster with lower risk early childbirth was $24 \%(\mathrm{MHR}=1.24,95 \%$ CI 1.21-1.27) higher. After accounting for predictors and interaction term the median increase in the hazard of early childbirth when comparing a woman at a cluster with higher risk of early childbirth to a woman at a cluster with lower risk of early

Table 5 Parametric shared frailty model comparison on time to first birth data of reproductive age women in Ethiopia, 2016 EDHS

\begin{tabular}{llllll}
\hline Model & Log-likelihood & DF & AIC & Variance of $\theta$ & LR test of $\theta=0$ \\
\hline Lognormal gamma & 4511.66 & 34 & -8955.31 & 0.18 & $<0.001$ \\
Lognormal inverse Gaussian & 4511.62 & 34 & -8955.24 & 0.25 & $<0.001$ \\
Log logistic gamma & 4881.54 & 34 & -9695.08 & 0.23 & $<0.001$ \\
Log logistic inverse Gaussian & 4936.02 & 34 & -9804.03 & 0.87 & $<0.001$ \\
Inverse Weibull gamma & 5708.19 & 34 & $-11,348.37$ & 0.028 & $<0.001^{\text {a }}$ \\
Inverse Weibull inverse Gaussian & 5707.78 & 34 & $-11,347.55$ & 0.028 & $<0.001$ \\
\hline
\end{tabular}

a Preferred model 
Table 6 Bivariable and multivariable inverse-Weibull gamma shared frailty model on predictors of age at first birth among reproductive-age women in Ethiopia, EDHS, 2016

\begin{tabular}{|c|c|c|c|c|c|}
\hline \multirow{2}{*}{$\frac{\text { Variable }}{\text { Log-likelihood }}$} & \multirow{2}{*}{$\frac{\text { Null model }}{-1036.84}$} & \multicolumn{3}{|c|}{ First birth status } & \multirow[t]{2}{*}{ Full model } \\
\hline & & & & 5907.45 & \\
\hline Effect size & & Gave & Not gave & $\mathrm{CHR}$ & AHR \\
\hline \multicolumn{6}{|l|}{ Region } \\
\hline Most urban & & 474 & 568 & 1 & 1 \\
\hline Northern & & 3224 & 1603 & $1.08(1.01-1.18)^{* *}$ & $1.08(0.97-1.19)$ \\
\hline Oromia & & 4130 & 1552 & $1.07(0.98-1.18)^{*}$ & $1.18(1.06-1.30)^{* * *}$ \\
\hline SNNP & & 2192 & 1090 & $0.98(0.90-1.18)$ & $1.19(1.06-1.33)^{* * *}$ \\
\hline Eastern & & 424 & 161 & $1.00(0.92-1.09)$ & $1.16(105-1.28)^{* * *}$ \\
\hline Western & & 144 & 60 & $1.12(1.03-1.22)^{* *}$ & $1.37(1.24-1.52)^{* * *}$ \\
\hline \multicolumn{6}{|l|}{ Residence } \\
\hline Urban & & 1769 & 1678 & 1 & 1 \\
\hline Rural & & 8818 & 3357 & $0.96(0.91-1.02)$ & $1.09(0.98-1.19)$ \\
\hline \multicolumn{6}{|l|}{ Education } \\
\hline No education & & 6785 & 684 & 1 & 1 \\
\hline Primary & & 2865 & 2610 & $1.72(1.64-1.82)^{* * *}$ & $1.12(1.05-1.19)$ \\
\hline Secondary & & 593 & 1209 & $0.83(0.76-0.87)^{* * *}$ & $0.86(0.78-0.96)^{* * *}$ \\
\hline Higher & & 344 & 524 & $0.72(0.65-.80)^{* * *}$ & $0.75(0.65-0.85)^{* * *}$ \\
\hline \multicolumn{6}{|l|}{ Occupation } \\
\hline Not working & & 5243 & 2556 & $1.18(1.13-1.24)^{* * *}$ & $0.98(0.92-1.04)$ \\
\hline Agriculture & & 2522 & 726 & $0.98(0.93-1.04)$ & $0.94(0.88-1.02)$ \\
\hline Nonagriculture & & 2822 & 1754 & 1 & 1 \\
\hline \multicolumn{6}{|l|}{ Wealth index } \\
\hline Poorest & & 2060 & 570 & 1 & 1 \\
\hline Poorer & & 2122 & 681 & $1.03(0.96-1.10)$ & $0.98(0.91-1.05)$ \\
\hline Middle & & 2128 & 840 & $1.12(1.05-1.21)^{* * *}$ & $1.00(0.93-1.09)$ \\
\hline Richer & & 2089 & 1001 & $1.12(1.05-1.21)^{* * *}$ & $1.10(1.01-1.19)^{*}$ \\
\hline Richest & & 2190 & 1941 & $1.12(1.05-1.21)^{* * *}$ & $1.08(0.97-1.15)$ \\
\hline \multicolumn{6}{|l|}{ Spousal age diffe } \\
\hline$<5$ years & & 2984 & 342 & 1 & 1 \\
\hline$\geq 5$ years & & 6366 & 501 & $1.26(1.21-1.33)^{* * *}$ & $1.11(1.05-1.16)^{* * *}$ \\
\hline \multicolumn{6}{|l|}{ Contraceptive } \\
\hline Ever not use & & 4617 & 4278 & 1 & 1 \\
\hline Ever use & & 5970 & 757 & $0.50(0.48-0.52)^{* * *}$ & $0.91(0.86-0.97)^{* * *}$ \\
\hline \multicolumn{6}{|l|}{ Media exposure } \\
\hline No & & 8342 & 3166 & 1 & 1 \\
\hline Yes & & 2245 & 1870 & $1.10(1.04-1.15)^{* * *}$ & $1.01(0.94-1.08)$ \\
\hline \multicolumn{6}{|c|}{ Age at first marriage } \\
\hline$<15$ years & & 2915 & 129 & $9.10(8.83-9.86)^{* * *}$ & $1.26(0.87-1.82)$ \\
\hline $15-17$ years & & 3890 & 366 & $3.47(3.30-3.64)^{* * *}$ & $2.33(2.08-2.63)^{* * *}$ \\
\hline$\geq 18$ years & & 3689 & 611 & 1 & 1 \\
\hline \multicolumn{6}{|l|}{ Age at first sex } \\
\hline$<15$ years & & 2860 & 167 & $1.89(1.78-1.99)^{* * * *}$ & $27.78(23.26-32.26)^{* * *}$ \\
\hline $15-17$ years & & 4576 & 486 & $0.68(0.65-0.71)^{* * *}$ & $2.60(2.07-2.63)^{* * *}$ \\
\hline$\geq 18$ years & & 3151 & 4395 & 1 & 1 \\
\hline \multicolumn{6}{|c|}{ Husband education } \\
\hline No Edu- & & 4516 & 234 & 1 & 1 \\
\hline Primary & & 3454 & 311 & $0.99(0.94-104)$ & $1.03(0.97-1.09)$ \\
\hline Secondary & & 808 & 163 & $0.88(0.81-0.95)^{* * *}$ & $1.05(0.96-1.15)$ \\
\hline Higher & & 573 & 134 & $0.68(0.63-0.74)^{* * *}$ & $1.03(0.93-1.14)$ \\
\hline
\end{tabular}


Table 6 (continued)

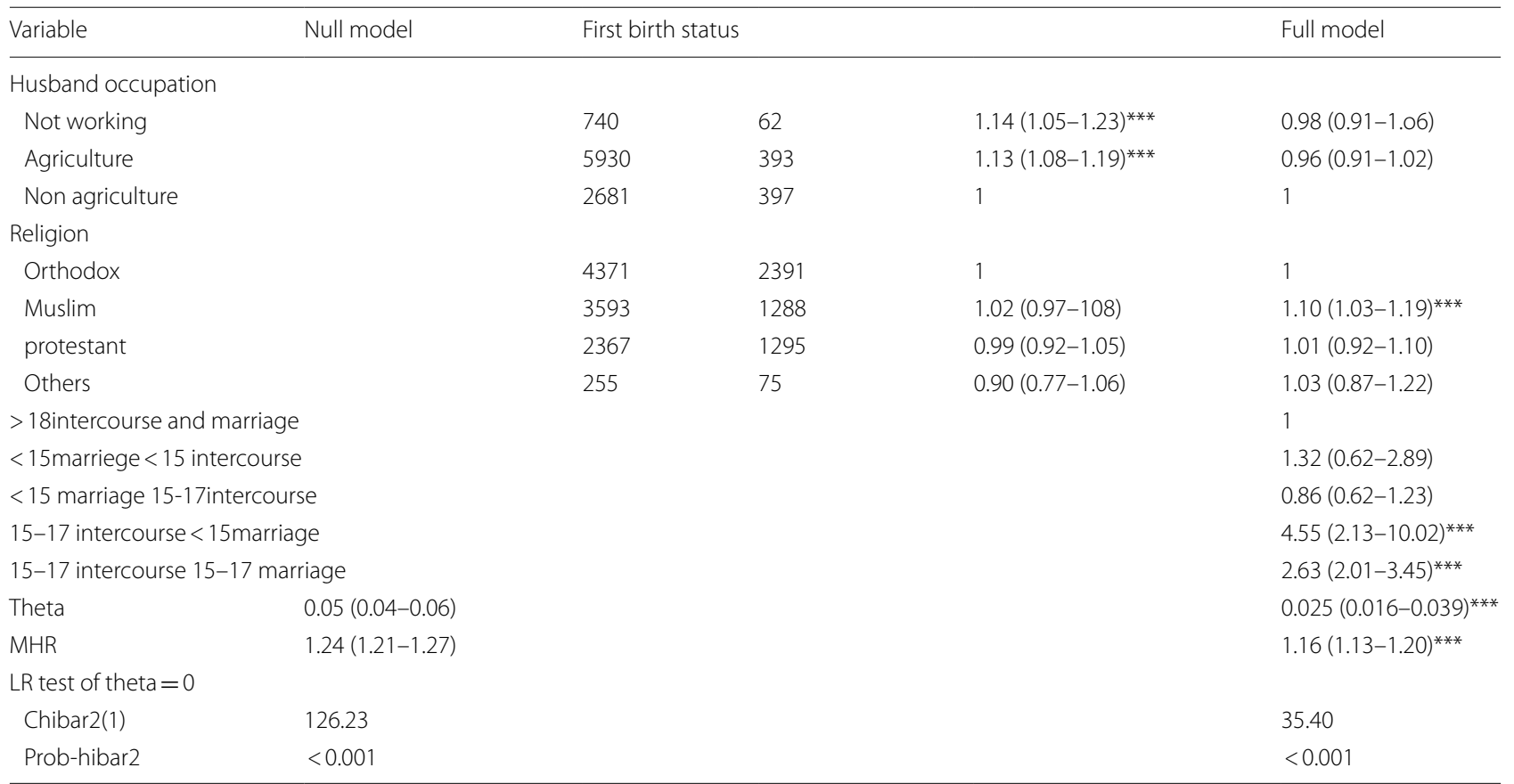

*significant at $90 \%$ Confidence level; ${ }^{* *}$ significant at $95 \%$ confidence level; ${ }^{* * *}$ significant at $99 \%$ confidence level

$\mathrm{MHR}=$ median hazard ratio, $\uparrow$ from interaction model

childbirth was $16 \%(\mathrm{MHR}=1.16,95 \%$ CI $[1.13-1.20])$ (Table 6).

The hazard of early childbirth was higher among Muslim religion followers by $10 \%$ than orthodox followers given that they were in the same cluster and control for other factors (AHR $=1.10,95 \%, \mathrm{CI} 1.03-1.19)$.

In addition to main effect the interaction term revealed that those married before the age of 15 and enter into sexual intercourse at the age of 15-17 years had an increased hazard of first birth at an early age by (AHR $=4.55,95 \%$ CI 2.13-10.02) than who were enter into sexual intercourse with marriage at the age of 18 and later. The hazard of an early childbirth increased by (AHR $=2.63,95 \%$ CI 2.01-3.45) times among women had sexual intercourse at marriage 15-17 years than who were married 18 years and later.

\section{Model adequacy}

The Cox-Snell residuals versus the Nelson-Aalen cumulative hazard function were obtained by fitting the cox gamma shared frailty, inverse Weibull gamma shared frailty, log-logistic inverse Gaussian frailty and lognormal gamma shared frailty models. The Nelson Aalen cumulative hazard function against the Cox-Snell residuals has a linear pattern making a straight line through the origin of the inverse Weibull gamma shared frailty model when compared to the rest models. This suggests that the inverse Weibull gamma shared frailty model provided the best fit for the time to first birth data analysis (Fig. 5).

\section{Discussion}

This study was set out to examine the timing of first birth among reproductive-age women in Ethiopia and modeled factors affecting it using a parametric shared frailty analysis method. The study revealed that majority of women gave their first birth at an early age and age at first marriage, age at first sexual intercourse and women education were most significant factors.

In the current study, the median age at first birth found to be 20 years. This finding is in agreement with the finding of, Martial Island, Ghana, and Nigeria where the median age at first birth was 19.91 years in Ghana, 20 years in Nigeria to 20.2 years in Martial Island [8, 24, 33]. This might be due to the high prevalence of early marriage and sexual intercourse activities in these countries $[47,48]$. Early marriage compromise women's decision role in her reproductive health and resulted in early childbirth [49]. The other possible justification for this similarity might be due to the limited educational opportunity of girls in these countries as the majority of the population lived in the rural area [50], which forces them 

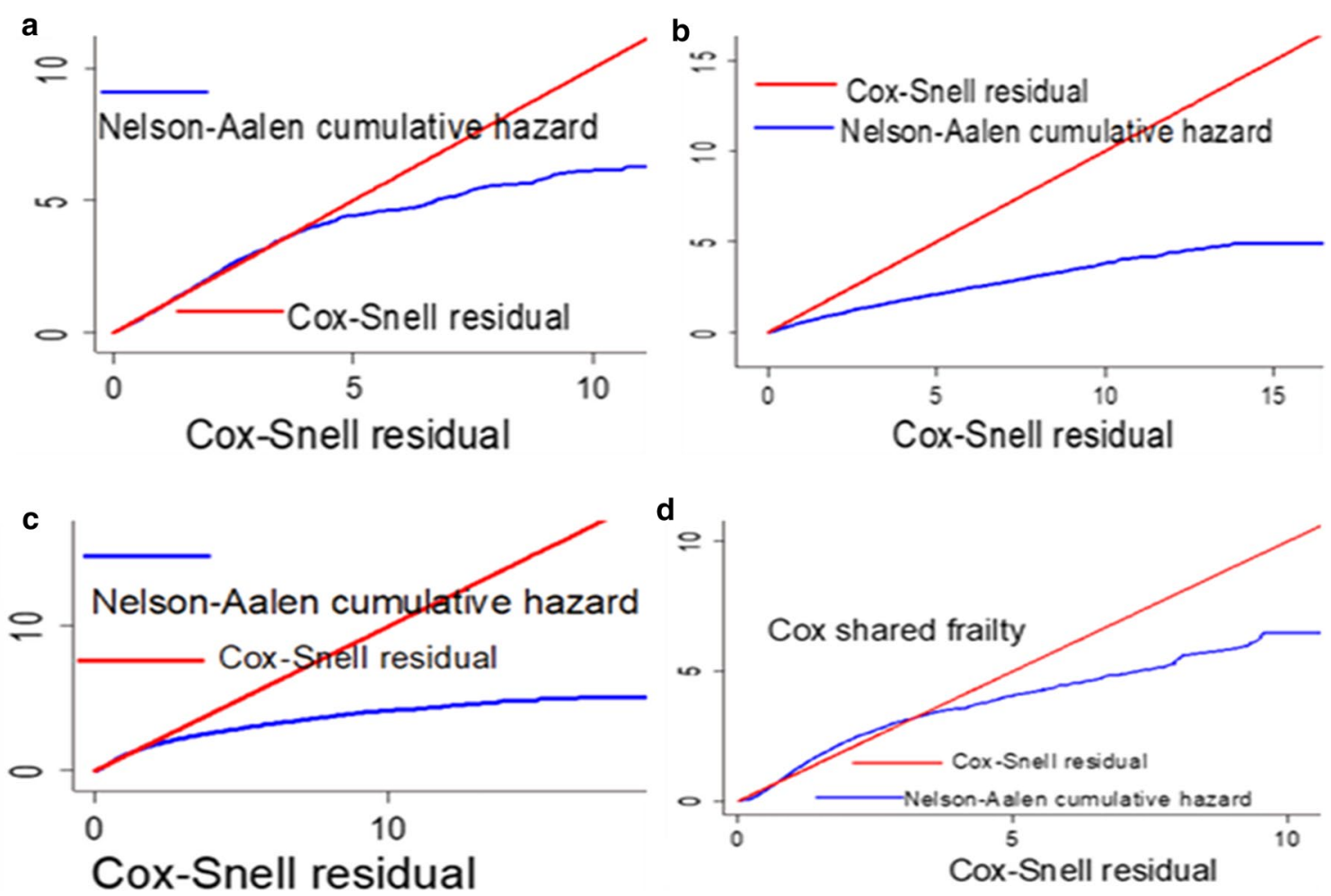

Fig. 5 Cox-Snell residual and Nelson Aalen cumulative hazard plots of time to first birth in Ethiopia, 2016, EDHS. a Inverse-Weibull gamma shared frailty. $\mathbf{b}$ Log-logistic inverse Gaussian shared frailty. c Lognormal gamma shared frailty. $\mathbf{d}$ Cox gamma shared

to get married at an early age, to get social and financial support [51,52].

However, our result was far lower than the median ages ( $>30$ years) in most developed countries $[3,53]$. This might be due to a higher opportunity for girls to stay in school for their adolescent age and a number of women going out to work for their economic independence [3] which help mothers to delay their first birth. It is also well justified with the awareness of women in developed countries about the consequences of early childbirth and having access to contraceptives to delay first birth in these countries [51]. Moreover, women in developed countries have the chance to exercise their reproductive rights and make a decision regarding their reproductive health issues [51].

On the other hand, our finding was higher than the finding in in Degua Tembien District, Tigray, Ethiopia [26] and in Bangladesh [23]. This variation could be due to difference in study design and small sample size in the former study and difference in study period which was in 2011 Bangladesh Demographic and Health Survey (BDHS). Moreover, in the latter case the variation might also be explained with difference in socio-cultural and religious affiliation, since $89 \%$ of the population Bangladesh was Muslims [54] whereas not more than $31 \%$ in
Ethiopia [44]. Muslim women have their first births earlier than non-Muslim women [23, 25].

Women who were started sexual intercourse at an early age had higher hazards of having first birth at an early age than those who were started intercourse at a later age. This outcome is in concurrence with studies conducted in Ghana [24], Bangladeshi [20] and Swaziland [9]. This might be due to the exclusion of adolescents from education and sociocultural miss-conception regarding female reproductive health issues and poor legal backing of women in these developing countries. This argument is supported by the United Nation (UN) report stating that still, one-half (49.8\%) of the female youth population had either no education or limited education in developing countries [55].

Age at first cohabitation was also another predictor of time to first birth, as women got married early, the hazard of early motherhood at an early age was increased. This is in agreement with studies conducted in Bangladesh [23],Nigeria [33] and other many studies conducted elsewhere $[3,4,7,14,19,20,22,26,31,32]$. It is apparent that marriage increases the frequency of fertile sexual intercourses and as it happened in early, it leads motherhood at an early age [22]. This is consistent with previous evidence that shows marriage is not planned and desire 
for women in developing countries rather a requirement to get an economic guarantee and social respect by keeping virginity at marriage [52]. In most cases, young housewives are characterized by lower educational attainment, lack of adequate formation about the negative consequences of early childbearing, are economic dependent on their spouses and limited to no role in the decision-making process which fundamentally restricts their capability to delay their childbearing to older ages [49].

In addition to main effects the interactions terms between age at first sexual intercourse and age at first marriage revealed those in married stratum in early age were positively associated with early age childbirth and those in not married stratum were negatively associated with early childbirth. It might be due to that in Ethiopia marriage provides normative legalization for childbirth. So, even sexual intercourse happened in an early age unless supported with marriage probability of childbirth is minimal in Ethiopia.

Higher spousal age gap among women was found to be linked with higher early age maternity. This result was in agreement with reports in Nigeria [33] and Bangladesh [23]. Possible reasons might be that higher spousal age difference may cause imbalanced power relations in the family and low level of inter-spouse communication which fundamentally translate into women's participation in the family decision-making process including the decision to use contraceptives $[49,52]$.

Women's education and early motherhood were inversely associated in this study. This finding was corroborate with study findings in Degua Tembien District, Tigray, Northern Ethiopia [26], Bangladeshi [1] and results elsewhere $[3,4,7,14,19,21,22,26,31-35$, 41-43]. In particular, ensuring those adolescent girls to receive at least a secondary level of education is the optimal way of delaying childbirth [53, 58]. Possible explanations of the inverse association between educational attainment and motherhood at an early age could be due to that enrolling and retaining girls at least up to a secondary level of education probably reduce early marriage and sexual experience and increase awareness of reproductive health issues $[50,56]$. In contrast, women at lower education level have lack of adequate knowledge about the high-risk period of becoming pregnant, are not fully aware of family planning methods and the costs of early childbearing on mothers and children health [57].

Regarding region of residence Oromia, SNNP, Eastern pastoralist and western semi-pastoralist regions significantly increased the hazard of first birth at an early age compared to most urban regions (Addis Ababa, Dire Dawa, and Harare), controlling for other factors and holding cluster effect the same. This finding was coherent with the study reported in Ethiopia [58] and Ghana [24]. This might be due to fewer proportions of educated women, and access to contraceptive and reproductive health issues in rural regions [44]. Furthermore, women in rural regions might have less decision making role regarding their reproductive health and timing of first birth.

One contrasting finding in this study was the richer wealth index associated with an increased hazard of first birth at an early age compared to the poorest in the full model. The possible reason may be as $78 \%$ of women in Ethiopia are rural dwellers [44] and in most rural areas wealth is one precondition for marriage as "macha", which is an amalgamation of wealth from families for the new couples. So those girls from richer families got married early in their lives and became mothers in adolescent age.

Ever use of contraceptive linked to the delay of the first birth than none user counterparts in this study. This result is in agreement with findings documented in Northeast Ethiopia [39], East Asia [8] and studies elsewhere $[3,7,19,31,33,37,40]$. It might be due to the fact that as far as the appropriate utilization of contraceptive, sexually active women may able to delay unintended pregnancies and births.

Muslim women had their first births earlier than orthodox women. This might be due to normative pressure and traditional cultures of Muslims influence women not to use a contraceptive. It is supported with $68 \%$ of Muslims were not used any form contraceptive compared to only $47 \%$ orthodoxies were not used in 2016, EDHS [44]. The other justification could be the ignorance of Muslim women. It is also supported by the EDHS report that more than $90 \%$ of Muslim women were had primary and no education level [44]. This finding was in concurrence with findings in Bangladesh [23] and Nigeria [25] where $90 \%$ and $50 \%$ of the population were Muslim religion followers.

The study findings should be interpreted in light of numerous limitations. First, the analysis is based on selfreported information and thus is subject to self-report bias (recall and social desirability bias). For example, there is possibly under-reporting of births ended with death. The choice of predictors in the analysis was also limited to background characteristics. There was the possibility, that other variables not included in the analysis significantly affect time to first birth like parental education and economic status. Some variables like religion are time varying to predict the outcome since current religion only considered in the study.

These limitations notwithstanding, the findings highlight some key factors that are likely to be significant drivers of early entry into motherhood and in a far advanced 
age at first birth among reproductive-age women in Ethiopia. A key strength of this study is the use of a nationally representative and population-based data to model the timing of first births among reproductive-age women in Ethiopia which make the result to be generalized to the reproductive age women in Ethiopia and similar developing countries.

Another important strength of the finding was accounting for the contextual effect which helps to design strategies for context-based interventions. In statistical analysis the possible suitable model for the data considered.

\section{Conclusion}

In this study, the median age at first birth was found to be 20 years which was at a lower boundary of the optimum age to first birth 20-29 years. Early age at first marriage, sexual intercourse, high spousal age difference, and being Muslim religion followers were predictors of first birth at an early age. On the other hand secondary and higher education levels, living in the most urban regions, contraceptive use were factors to delay first birth.

Early childbirth, which was often originated from early marriage and sexual behavior, result in potential health risks for the young mother and their child, as well as the termination of education and blurred future job prospects. Therefore we recommend: the ministry of women and children affairs' to introduce programs aiming to reduce early sexual intercourse very early, and before the commencement of the sexual activity.

Better to avoid marriage at an early age and high spousal age difference by teaching the community and enforcing legal marriage age. The Ministry of Education recommended retaining women to at least a secondary education level and higher by extending the accesses to rural dominant and pastoralist regions. The Ministry of Health also better to maximize utilization of contraceptives by increasing access and promoting friendly methods as well.

Researchers better to conduct researches incorporating family factors and investigate what factors may influence in Muslim religion followers to give first birth at an early age.

Better to explore factor associated with delayed first birth among urban region residents and those had secondary and higher education.

\section{Abbreviations}

AHR: Adjusted hazard ratio; AIC: Akaike information criterion; ATR: Adjusted time ratio; CSA: Central statistics agency; CSPro: Census survey program; EAs: Enumeration areas; EDHS: Ethiopian demographic health survey; GG: Generalized gamma; IW: Inverse Weibull; IQR: Interquartile range; MHR: Median hazard ratio; $\mathrm{PH}$ : Proportional hazard; PO: Proportional odds; WHO: World Health Organization.

\section{Acknowledgements}

We are deeply grateful to Mr. Getahun Molla (MPH), Mr. Dessie Abebaw (MPH), Mr. Yigizie Yeshaw (MSC) Mr. Baye Dagnew (MSC) and Mr. Adugnaw Zeleke always they found time to provide constructive feedback to our thoughts. We acknowledge University of Gondar for its general support and willingness to conduct this study and measure DHS for their permission to use EDHS data.

\section{Authors' contributions}

RD, FA and WS were involved in conception, design and analysis of the study, $\mathrm{RD}$ interpretation and drafting the manuscript. FA and WS were reviewing the manuscript. All authors read and approved the final manuscript.

\section{Funding}

There was no specific funding for the research.

\section{Availability of data and materials}

The data underlying the study can be accessed after legal registration at www. measuredhs.com. After registration, interested researchers to conduct study can log in at https://www.dhsprogram.com/data/dataset_admin/login_main. $\mathrm{cfm}$ and access the data as zipped files.

\section{Declarations}

\section{Ethics approval and consent to participate}

The written approval letter was obtained from the DHS International Program to use the data for this analysis which authorized for the data-sets.

\section{Consent for publication}

Not applicable.

\section{Competing interests}

The authors declare that they have no competing interests.

\section{Author details}

${ }^{1}$ Department of Epidemiology and Biostatistics, School of Public Health, College of Medicine and Health Science, Wollo University, Dessie, Ethiopia.

${ }^{2}$ Department of Epidemiology and Biostatistics, Institute of Public Health, College of Medicine and Health Sciences, University of Gondar, Gondar, Ethiopia.

Received: 8 January 2020 Accepted: 8 March 2021

Published online: 19 March 2021

\section{References}

1. Mohammad A, Rabbi F, Kabir MHMI. Factors influencing age at first birth of Bangladeshi women - a multivariate approach. Am J Public Health Res. 2013;1(7):191-5.

2. Mathews TJ, Hamilton BE. Delayed Childbearing : more women are having their first child later in life; 2009.

3. SIRC. The changing face of motherhood, vol 44; 2011.

4. Temin M, Levine R. A new agenda for global health; 2009.

5. Campbell B, Martinelli-heckadon S, Wong S. Motherhood in childhood; 2013.

6. Kassa GM, Arowojolu AO, Odukogbe AA, Yalew AW. Prevalence and determinants of adolescent pregnancy in Africa: a systematic review and meta-analysis. Reprod Health. 2018;15(195):1-17.

7. Patton GC, Coff C, Sawyer SM, Viner RM, Haller DM, Bose K, et al. Global patterns of mortality in young people: a systematic analysis of population health data. Lancet. 2009;374:881-92.

8. Kennedy E, Gray N, Azzopardi P, Creati M. Adolescent fertility and family planning in East Asia and the Pacific: a review of DHS reports. Reprod Health [Internet]. 2011;8(1):1-12.

9. Honours SN-M. Demographic and socio-economic determinants of age at first birth in Swaziland. 2017;1-6.

10. Usta IM, Nassar AH. A review of the risks and consequences of adolescent pregnancy. J Neonatal Perinatal Med. 2015;2015(8):1-8.

11. Al Cl et al. Comparative quantification of health risks global and regional burden of disease attributable to selected major risk factors. 2004;1-1200. 
12. Karra M, Lee M. Human capital consequences of teenage childbearing in trends in South African teen. 2012:1-5.

13. Chang Z, Lichtenstein P, Onofrio BMD, Almqvist C, Kuja-halkola R, Sjo A. Original article Maternal age at childbirth and risk for ADHD in offspring: a population-based cohort study. Int J Epidemiol. 2014;43(October):1815-24.

14. Beguy D, Ndugwa R, Kabiru CW. Entry into motherhood among adolescent girls in two informal settlements in Nairobi, Kenya. J Biosoc Sci. 2013:45:721-42.

15. Dupont J, Ngowa K, Kasia JM, Pisoh WD, Ngassam A, Noa C. Obstetrical and perinatal outcomes of adolescent pregnancies in Cameroon: a retrospective cohort study at the Yaoundé General Hospital. Open J Obste Gynecol . 2015;5:88-93.

16. Sakai T, Sugawara Y, Watanabe I, Watanabe T, Tomata Y, Nakaya N. Age at first birth and long-term mortality for mothers: the Ohsaki cohort study. Environ Health Prev Med. 2017;22(24):1-14

17. WHO U. Preventing early pregnancy and poor reproductive outcomes among adolescents in developing countries: what the evidence says; 2008.

18. Jacobsson $B$, Ladfors $L$, Milsom I. Advanced maternal age and adverse perinatal outcome. Am Coll Obstet Gynecol. 2001;104(4):727-33.

19. Valadan M, Tanha FD, Sepahi A. Pregnancy outcomes in women of advanced age. J Fam Reprod Health. 2011;5(2):57-62.

20. Chowdhury AHMY, Rumana AS, Faisal A. Factors affecting age for first birth: an exploratory analysis on Bangladeshi women. Int J Res Stud Med Health Sci. 2017;2(7):31-7.

21. Zare N, Nouri B, Moradi F, Parvareh M. The study of waiting time to first pregnancy in the south of Iran: a parametric frailty model approach. Int J Reprod Biomed. 2017:15(1):11-6.

22. Central Statistical Agency [Ethiopia] and ICF International. 2012. Ethiopia demographic and health survey 2011. Report. Addis Ababa, Ethiopia and Calverton, Maryland, USA; 2012.

23. Mohammad S. Patterns and determinants of age at first birth in Bangladesh. Turk J Popul Stud. 2013;35:63-77.

24. Ida LA, Albert L. The statistical distribution and determinants of mother's age at first birth. Am J Theor Appl Stat. 2015;4(2):41-52.

25. Fagbamigbe AF, Idemudia ES. Survival analysis and prognostic factors of timing of first childbirth among women in Nigeria. BMC Pregnancy Childbirth [Internet]. 2016;16(102):1-12. https://doi.org/10.1186/s1288 4-016-0895-y.

26. Ayele BG, Gebregzabher TG, Hailu TT, Assefa A. Determinants of teenage pregnancy in Degua Tembien District, Tigray, Northern Ethiopia: a community-based case-control study. PLOS ONE. 2018;13:1-15.

27. Booklet D. World fertility patterns 2015; 2015.

28. Mohammad A, Rabbi F, Kabir M, Kabir R. What went wrong with the achievement of replacement fertility in Bangladesh and its consequences on the demographic dividend : the role of proximate determinants. Rom J Popul Stud. 2018;12(1):1-24.

29. Islam MM, Islam K, Hasan MS. Adolescent motherhood in Bangladesh: trends and determinants. PLoS ONE. 2017;13:1-14.

30. Habitu YA, Yalew A, Bisetegn TA. Prevalence and factors associated with teenage pregnancy, Northeast Ethiopia, 2017: a cross-sectional study. Hindawi J Pregnancy. 2018;2018:1-8.

31. Singh SGARD. The effect of early marriages and early childbearing on women's nutritional status in India. Matern Child Health J. 2015:19:2-20.

32. Pandey A, Nath DC. Frailty approach to age at first birth in Uttar. J Math Stat Oper Res. 2015;3(1):30-5.

33. Michael O, Kunnuji N. A survival analysis of the timing of onset of childbearing among young females in Nigeria: are predictors the same across regions ? Reprod Health. 2018;15(173):1-9.

34. Gurmu E, Etana D. Age at first marriage and first birth interval in Ethiopia: analysis of the roles of social and demographic factors. Afr Popul Stud. 2014;28(3):1332-44.

35. Mekonnen Y, Telake DS, Wolde E. Adolescent childbearing trends and sub- national variations in Ethiopia: a pooled analysis of data from six surveys. BMC Pregnancy Childbirth. 2018:18(276):1-13.
36. Babalola S, Oyenubi O, Speizer IS, Cobb L, Akiode A, Odeku M. Factors affecting the achievement of fertility intentions in urban Nigeria: analysis of longitudinal data. BMC Public Health. 2017;17(942):1-8.

37. Yakubu I. Determinants of adolescent pregnancy in sub-Saharan Africa: a systematic review. Reprod Health. 2018;15(15):1-11.

38. Mathews TJ, Hamilton BE. Mean age of mothers is on the rise: United States, 2000-2014. NCHS Data Brief. 2016;232:1-8.

39. Habitu YA, Yalew A, Bisetegn TA. Prevalence and factors associated with teenage pregnancy, Northeast Ethiopia, 2017: a cross-sectional study. J Pregnancy. 2018;2018:1-7.

40. Brahmbhatt $H$, Kågesten A, Emerson M, Decker MR, et al. Prevalence and determinants of adolescent pregnancy in urban disadvantaged settings across five cities. J Adolesc Health. 2014;55(6):S48-57. https://doi. org/10.1016/j.jadohealth.2014.07.023.

41. Chernet AG, Shebeshi DS, Banbeta A. Determinant of time-to-first birth interval after marriage among Ethiopian women. BMC Womens Health. 2019;19(1):1-6

42. Rossierl C. Abortion: an open secret? Abortion and social network involvement in Burkina Faso. Reprod Health Matters. 2007;15(30):230-8.

43. Guidelines U. Distinguishing the impact of postponement, spacing and stopping on birth intervals: fecundity. J Biosoc Sci. 2013;45:311-30.

44. Central Statistical Agency (CSA) [Ethiopia] and ICF. 2016. Ethiopia demographic and health survey 2016. Addis Ababa, Ethiopia, and Rockville, Maryland, USA; 2016

45. Croft TN, Marshall AMJ, Allen CK, et al. Guide to DHS statistics. Maryland: Rockville; 2018

46. Dewau R, Muche A, Fentaw Z, Yalew M, Bitew G, Amsalu ET, et al. Time to initiation of antenatal care and its predictors among pregnant women in Ethiopia: Cox-gamma shared frailty model. PLoS ONE. 2021;16:1-18. https ://doi.org/10.1371/journal.pone.0246349.

47. Walker J. Early marriage in Africa-trends, harmful effects and interventions. Afr J Reprod. 2012;16(2):231-40.

48. Adebowale SA, Fagbamigbe FA, Okareh TO, Lawal GO. Survival analysis of timing of first marriage among women of reproductive age in Nigeria: regional differences. Afr J Reprod Health. 2012;16(4):95-107.

49. UNICEF. Early marriage: child spouses. Innocenti Digest No. 7. 2001, vol, Innocenti; 2001.

50. Mahy M. Adolescent childbearing in sub-Saharan Africa: can increased schooling alone raise ages at first birth? Neeru Gupta Demogr Res. 2003;8(4):93-106.

51. Merrill RM. Reproductive Epidemiology Principles and Methods. Chapman T, editor. Michael Brown; 2010:1-386.

52. The United Nations Children's Fund (UNICEF) 2005. Early marriage a harmful traditional practice a statistical exploration early marriage a harmful traditional practice a statistical exploration contents; 2005.

53. OECD. Mean age of mothers at first childbirth; 2014.

54. International Religious Freedom. Bangladesh 2019 international religious freedom report; 2019. https://www.state.gov/wp-content/uploa ds/2019/05/BANGLADESH-2018-INTERNATIONAL-RELIGIOUS-FREEDOMREPORT.pdf.

55. Elder S, Kring S. Young and female-a double strike? 2016.

56. Ferré $C$. Age at first child does education delay fertility timing? The case of Kenya. 2009. Report No.: 4833.

57. Angeles G, Guilkey DK, Mroz TA, Street WF, Hill C. The effects of education and family planning programs on fertility in Indonesia. Carolina at Chapel Hill; 2003.

58. Mekonnen Y, Telake DS, Wolde E. Adolescent childbearing trends and sub-national variations in Ethiopia: a pooled analysis of data from six surveys. BMC Pregnancy Childbirth. 2018;18(276):1-13.

\section{Publisher's Note}

Springer Nature remains neutral with regard to jurisdictional claims in published maps and institutional affiliations. 